\title{
The devil's in the theory: a critical assessment of Robert Chambers' work on participatory development
}

\section{ILAN KAPOOR}

ABSTRACT The practice orientation of Robert Chambers' work on Participatory Rural Appraisal (PRA), which aims at enabling local people and communities to take control over their own development, has received much attention in development circles. This article attempts to shift the emphasis away from PRA's practice towards its theoretical underpinnings. The article argues that PRA's practice/ empiricist orientation causes it to be insufficiently theorised and politicised. As a result, questions about inclusiveness, the role of PRA facilitators, and the personal behaviour of elites overshadow, or sometimes ignore, questions of legitimacy, justice, power and the politics of gender and difference. The article draws on arguments and debates involving Habermasian 'deliberative democracy' and post-structuralist notions of power.

Most of those who have innovated in developing PRA have been practitioners, concerned with what works, and what will work better, not academic theorists concerned with why it works. They have been searching not for new theories or principles but for new and better ways of learning and doing. For them, the power and utility of ... PRA, undertaken with rapport and self-critical rigor, are empirical facts of common experience: they know that they work, and that done well they can lead to better development. (Chambers, 1994b: 1262)

Robert Chambers' work on Participatory Rural Appraisal (PRA) has become remarkably influential in NGO circles and among national and international development agencies. PRA champions local knowledge and puts forth a methodology aimed at enabling local people to take control over their own development. The practice orientation of this methodology is perhaps what contributes to its influence among development organisations, whose activities emphasise programme delivery. This practice orientation probably also explains why the vast majority of the literature assessing PRA has focused mainly on its successes and failures in the field (eg Blackburn \& Holland, 1998; Holland \& Blackburn 1998; Nelson \& Wright, 1995). Yet methodologies carry with them philosophical and theoretical predilections that equally warrant examination. This article is a step in that direction. ${ }^{1}$

To start, I would like to argue that it is, in particular, the empiricist predilection

Ilan Kapoor is in the Faculty of Environmental Studies, York University, 4700 Keele Street, Toronto, Ontario, Canada M3J IP3.E-mail: ikapoor@yorku.ca. 
of Chambers' work that requires closer examination; later, I will attempt to show how this predilection leads to insufficient attention to such critical issues as legitimacy and justice in participatory development. The empiricist predilection is evident in the epigraph above, and it is underscored repeatedly by Chambers. He writes that the principles of PRA 'have been induced rather than deduced; they have been elicited by trying out practices, finding what works and what does not, and then asking why'. (1994b: 1254) And he continues with: 'PRA as it is emerging is experiential, not metaphysical. Theory has been induced from practice, from what is found to work, not deduced from propositions. Good performance has been sought through empiricism' (1994c: 1449). Thus, 'common experience' is privileged over theory; and 'practice', as opposed to 'metaphysics', is emphasised as authoritative and meaningful.

But this empiricism brings with it a number of pitfalls. Taking 'what is' and 'what is done' as given is not conducive to questioning and critique. From a methodological point of view, the resulting tendency is to get bogged down in methods and techniques without stopping adequately to consider initial assumptions or broader issues (eg about the purpose of the techniques). When something goes amiss in practice, Chambers' response is to find better ways of doing it: his 'and then asking why' is not about asking 'why are we doing what we are doing?' but 'why does it not work?'. Because Chambers' inductivism is opposed to 'metaphysics', any problem encountered in practice is addressed through more and better practice, not fundamental questioning. Chambers appears to construct a practice/theory binary opposition that teeters on the fetishisation of practice and the impoverishment of theory, a point which will be pursued below.

Empiricism has political ramifications, too. To privilege 'what is' is often to unquestioningly accept the status quo, for instance a situation of gender or social inequality. The lack of a critical stance can mean simplifying or ignoring broader relationships between, say, local communities and socioeconomic power structures. Similarly, to privilege 'what works and what does not' is to downplay such important political questions as 'what works for whom?' and 'whose interests are being served?'. The danger of fetishising practice is that it tends to posit a 'pure' practice that can proceed without bias or theoretical abstractions, independent of, and unfettered by, political concerns about justice and legitimacy. One would be hard pressed to induce any meaningful practice from a situation of socioeconomic inequality or exclusion, let alone inducing a 'just' or 'legitimate' practice.

These methodological and political ramifications will be further developed in the remainder of this article, when we consider the details and implications of PRA. The point of highlighting Chambers' empiricist leanings at this initial stage is to suggest ways in which they frame his work, predisposing PRA to certain procedural and political problems. My argument is not that his work is empiricist through and through, or that PRA does not engage in any theorisation and political critique: Chambers' empiricism, after all, includes theory, but induces it from practice. My argument, rather, is that his empiricist orientation causes PRA to be insufficiently theorised and politicised. ${ }^{2}$ Questions about inclusiveness, the role of PRA facilitators, and the personal behaviour of elites overshadow, or sometimes ignore, questions of legitimacy, justice, power and the politics of gender 
and difference.

After examining the details of PRA, the article will look into the lack of meaningful grounding of PRA practice and procedures. This discussion will be facilitated by comparing and contrasting PRA with Habermas's 'deliberative democracy'. While Habermas shares with Chambers an open-ended and proceduralist approach, his proceduralism, unlike Chambers', is grounded in communicative rationality. And although this communicative rationality is not without its own limitations, it prioritises political concerns about legitimacy and justice. The article will then move on to explore issues of power in PRA. Here, it will be argued that Chambers' narrow view of power fails adequately to grapple with broader political-economy and gender issues. Moreover, it will be argued that, because of his lack of attention to theorisation about power, Chambers misses out on Foucault's important insights into power/knowledge, which help reveal the power dimensions inherent in PRA itself.

\section{Participatory Rural Appraisal (PRA)}

Chambers' work on PRA is developed primarily in three consecutive articles published in World Development (1994a; 1994b; 1994c) and a monograph, entitled Whose Reality Counts? (1997), which includes but also expands on much of the 1994 material. In these works, Chambers acknowledges PRA's indebtedness to a number of sources, ${ }^{3}$ but he repeatedly underlines how PRA draws on the cumulative experience and practice of mainly southern NGOs active in participatory development in the 1980s and 1990s. In a sense, Chambers presents himself as a kind of scribe, recording and retrospectively systematising the work of these NGOS; it is no wonder, then, that his work is both so heavily practice-orientated and attractive to development organisations working in the field.

As it is dependent on ongoing practice and experience, PRA is a methodolog $y^{4}$ that is open-ended and continually evolving. According to Chambers, the methodology was developed in response to the tendency within mainly Westerndominated development organisations to impose knowledge and plans on local communities. PRA is thus 'a family of approaches and methods to enable local (rural and urban) people to express, enhance, share and analyze their knowledge of life and conditions, to plan and to act' (1994b: 1253). PRA valorises local, as opposed to Western, knowledge and aims to empower people 'to determine much of the agenda' (1994b: 1255).

Two elements feature prominently in Chambers' work. The first is PRA's inclusiveness, so that all local community members can participate in PRA meetings and workshops. Particular attention is paid to including marginalised and disadvantaged groups: 'The poor, weak, vulnerable and exploited should come first' (1997: 11, emphasis in the original). Many of the PRA techniques (described below) subscribe to a broad definition of communication to accommodate differing levels of literacy and expressive styles. The second element is the role played by 'outsiders' in PRA, by which Chambers means any persons or organisations from outside the local community who can play a catalytic role in facilitating PRA. Chambers is especially concerned about (mostly 'Western') development personnel taking on the role of 'experts'. He devotes a lot of space 
in his work deriding the top-down methods used by some of these personnel, underlining how PRA stands for enhancing the learning, not of outsiders, but 'insiders', and how PRA is participatory, not extractive: 'The outsiders are convenors and facilitators, the insiders actors and analysts' (1994b: 1263). The goal is for local communities themselves to take over the role of convenors and facilitators.

In order to achieve these objectives and principles, PRA deploys a host of methods and techniques. Most techniques involve group-based learning and planning. An emphasis is placed on visual inputs to ensure that all community members can participate regardless of literacy levels. For example, shared visual representation and analysis may involve 'mapping' on the floor or 'ranking' exercises using seeds, stones or sticks. Some techniques use a combination of oral, written and visual communication. Often techniques are 'sequenced' (repeated over time) to maximise participation and gradually build a local knowledge base on a particular issue; and sometimes different techniques are used to investigate the same issue from a variety of angles ('plural investigation'). (1994a: 959; 1994b: 1254-1257, 1263)

The list and description of techniques is too long to enumerate, but here is a sample: 'do-it-yourself' and 'they do it' techniques that enable villagers to learn about various community activities, and to collect data (through interviews, observation, etc), analyse it and present relevant results; group 'transect walks' through a community area, in which group participants listen, ask questions, discuss environmental or health problems and seek solutions; oral histories (of community members); 'institutional' or 'chapati' or 'venn' diagramming to identify key community individuals and institutions and their relationships to one another; household profiles and histories; and participatory planning and budgeting. These PRA techniques are applied to a host of issues, ranging from natural resource management and agriculture to gender issues and poverty and social programming (1994a: 959-962).

\section{Questions of legitimacy, justice and difference}

Having outlined the main features of PRA, I would like to identify some of the gaps in its theorisation. These gaps have specifically to do with a lack of concern for building legitimacy into PRA procedures, ensuring just outcomes, and representing sociocultural difference. To this end, it is useful to compare PRA with Habermas's 'deliberative democracy' as there are important parallels, yet illuminating differences, between the two.

At one level, Habermas and Chambers appear poles apart, since the former is primarily a philosopher concerned with democratic theory, and the latter mainly a social scientist concerned with development practice. Yet the theory/practice imbalance between the two is precisely what I find instructive. The theoretical weaknesses in Chambers' empiricist orientation can be teased out through, so-tospeak, a 'Habermasian lens'. I do not wish to exaggerate the theory/practice imbalance between the two, however: as noted earlier, Chambers does have a theoretical framework (but, arguably, an insufficiently developed one); and Habermas's work has never been just theoretical. His writing reflects his active 
engagement as a public intellectual in German and European politics since the $1960 \mathrm{~s}^{5}$

\section{Legitimating procedures?}

Habermas elaborates a notion of the 'public sphere' as an autonomous space, separate from either economy or state, and in which citizens participate and act through dialogue and reasoned debate (Habermas, 1989; Calhoun, 1992). In more recent writings (eg 1996a; 1996b), Habermas develops the specifically deliberative aspects of the public sphere, arguing for the broadening of free speech to create and strengthen the foundations of democracy (hence the term 'deliberative democracy'). He shares with Chambers the priority of decentralising politics so as to counter the increasing monopolisation of power by the state. ${ }^{6}$ Habermas also shares with Chambers a 'proceduralist' view of participation, that is, a commitment to an open, dialogical process that refrains from foisting blueprints upon the public agenda or limiting it to specific issues.

But unlike Chambers, Habermas anchors his proceduralist democracy in reasoned debate and rules that give this proceduralism legitimacy: 'democratic will-formation draws its legitimating force ... from the communicative presuppositions that allow better arguments to come into play in various forms of deliberation and from the procedures that secure fair bargaining processes' (1996a: 24). For Habermas, deliberations need to be governed by formal conditions that are anticipated in the very resort to dialogue and that he calls an 'ideal speech situation'. T This ideal speech situation is one in which there is uncoerced rational dialogue among free and equal participants: the discussion is inclusive (ie no one is excluded from participating in the discussion on topics relevant to her/him), coercion free (ie people engage in arguments and counterarguments freely, without dominating others or feeling intimidated by others) and open (ie every participant can initiate and continue discussion on any relevant topic, including the very procedures governing the discussion) (Habermas, 1990: 88-89, 197; 1976: 107-109; Benhabib, 1996: 70).

Habermas does not believe it is easy to realise the ideal speech situation or that there are no important obstacles standing in its way (particularly removing or minimising power relations between participants). The ideal speech situation, for him, is not empirical. ${ }^{8}$ It is a regulative idea, a counterfactual stance from which to assess and challenge public deliberations and power politics. And, of late (1996b), as a way of guaranteeing, expanding and regulating deliberative democracy, Habermas has argued for the institutionalisation through legal and constitutional mechanisms of the formal rules mentioned above (more on the implications of this point below).

Chambers' PRA, in contrast, contains no systematic rules or 'legitimating force' governing participation and group interaction. As noted in the previous section, there is concern in PRA for inclusiveness, especially for the disadvantaged and women, with corresponding techniques to secure the presence of a wide variety of community interests at PRA meetings and workshops. There are also, as mentioned above, rules governing the behaviour of PRA facilitators and 'outsiders' to ensure that they, to use Chambers' expression, 'hand over the stick' 
and act with transparency, honesty, trust, self-critical awareness, humility, respect, interest and patience (1994b: 1253, 1256). But apart from the behaviour of the facilitators/outsiders, once participants are in the PRA meeting space, there are no explicit procedures covering their interactions. Chambers indirectly defends this lacuna by declaring that even 'minimal rules or controls' run the risk of codifying and formalising PRA in the 'name of quality' and at the expense of participants' spontaneity (1997: 200; 1994c: 1441).

Chambers is right to identify the dangers of over-codifying procedures; but he does not weigh these dangers against the crucial question of legitimating PRA procedures. What ensures that PRA discussions and interactions are coercion free? What prevents women and disadvantaged people, whom Chambers takes pains to bring into the PRA meeting, from feeling intimidated by authority figures also present? What allows participants to feel free to broach controversial topics or question the meeting's procedures? In short, what provisions exist for free and equal deliberations? One can infer that the onus for fair procedures is placed on the PRA facilitator (1994b: 1261). However, this solution raises more problems than it addresses: to grant the facilitator this role bestows upon her/him broad discretionary powers (eg intervening in discussions, taking sides for and against participants, etc) and superior 'expertise' that contradict Chambers' stated need to act with transparency, honesty, humility, respect, etc. In addition, to issue such discretionary powers to the facilitator, no matter the extent of her/his training, exposes these powers to potential abuse and corruption; and to entrust such powers in one participant diminishes those of other participants and compromises the very participatory purpose of PRA. Habermas averts the dangers of entrusting legitimisation to any person(s) by devising systematic procedures that are impartial-no one is above them, they apply to all without exception, and they can be questioned and revised by each participant in concert with all others.

PRA's inadequate systemisation and legitimisation of procedures has other implications, too. The informality of these procedures can raise doubt and mistrust on the part of local communities. Indeed, David Mosse draws attention to the suspicion among 'tribal' people in Madhya Pradesh, India of PRA informality, quoting a 'tribal' woman as saying: "'today you are sitting on the ground, tomorrow you will be sitting on our heads"' (1994: 505; see also Parpart, 2000: 228). PRA often appears new and foreign to communities unfamiliar with it; its informality may further reinforce this tendency. More serious, though, is that this informality can end up placing the onus of legitimacy on the commitment of its practitioners. In particular, it may increase the burden of local communities. If PRA is to be fair and credible, communities must invest extra energy, time and resources to come up with legitimating procedures for participation. In turn, this burden of time and commitment may have gender implications. As several analysts have pointed out, women's long working days (compared with men's) sometimes prevent them from participating in PRA altogether; and if these women do participate, their working day is stretched even longer, thereby further aggravating the gender division of labour (Mosse, 1994: 512; White, 1996).

Like Habermas, Chambers does call for the institutionalisation of PRA (1994c: 1447; Blackburn \& Holland, 1998); yet, for the reasons just noted, without the systematisation and legitimation of PRA procedures, such institutionalisation may 
prove counterproductive. The success of deliberative politics depends 'not on a collectively acting citizenry but on the institutionalization of the corresponding procedures and conditions of communication' (1996a: 27), writes Habermas. For such institutionalisation means that citizens can engage in deliberation even in informal settings, in what Habermas calls 'simple and episodic encounters' (1996b: 361). In this sense, the formality of legitimating procedures endows deliberative democracy with a degree of informality, allowing it to be integrated into people's daily lives; while the informality and lack of legitimating procedures in PRA ironically risk making local community life overly formal, thence burdening and disrupting people's daily lives.

\section{Just outcomes?}

But, for Habermas, legitimating procedures are not enough. Deliberative democracy must also produce just and equitable outcomes. To this end, as mentioned but not elaborated above, he grounds participation in rational discourse. It is reason that helps adjudicate between claims, thus yielding just decisions. However, Habermas has in mind here not an autonomous, individualised rationality, isolated from society and imposing its will without accountability. Instead, he opts for a dialogical, 'communicative' rationality, where citizens deliberate together, engaging in arguments and counter-arguments. A consensus is reached only through the (unforced) 'force of the better argument': it is an argument-driven consensus that everybody is convinced by and accepts as reasonable. The more deliberative the process, the more undistorted the communication and the more likely it is that the consensus will be acceptable by all concerned (Habermas, 1990: 88ff, 160, 198).

There are at least two sources for Habermas's claim to justice in a deliberative democracy. The first is that power relationships are minimised so that claims are assessed by their reasonableness, not by coercion or the socioeconomic status of the speaker. Policies are adopted when participants determine their rightness after listening to and debating pertinent arguments and reasons. Thus outcomes are just and equitable because reason triumphs over power (Young, 1996: 123). The second source of justice is that consensus is reached through a 'higher-level intersubjectivity of communication processes' (Habermas, 1996a: 28, emphasis in the original). Decisions are not reached by adding individual votes; they are achieved through qualitative discussion and collective compromise. Participants begin with individual interests, but transcend these interests as public deliberations gradually predispose them to seeking the good of all. Reasoned public deliberations help everyone reach an expanded view. The result is a movement from 'mere agreement' to 'rational consensus'.

It is important to underline the critical intention in Habermas's thinking here. Habermas is concerned 'not just with the ethical validity of laws' but also with being 'clear about the kind of society [people] want to live in'; this necessitates bringing "universal principles of justice into the horizon of the specific form of life of a particular community' (1996a: 24-25). In the attainment of a rational consensus, in the movement to a 'higher-level intersubjectivity', participants are likely to have to struggle and engage in critique. The to and fro of claim and 
counter-claim may involve, for example, both a critique of those institutions that are deemed to wield unreasonable socioeconomic power in the community and an appeal to universal human rights. Often, participants will need to debate and select one claim over another to reach consensus. The adjudicative function of reasoned debate, therefore, has an important critical function, helping to sort out differing claims, but also to criticise and minimise the impact of power and domination inside and outside the deliberative space. ${ }^{9}$

Like Habermas, Chambers orientates PRA to reaching concrete outcomes. $\mathrm{He}$ speaks of a 'consensus reality' (1994b: 1261) that local communities arrive at in order, for example, to improve farming systems, manage common property resources or make health interventions. But Chambers does not specify any grounding or mediating mechanism for reaching a just consensus. He has no equivalent to Habermas's communicative rationality. As indicated above, PRA offers multiple modes of communication (visual, verbal, written) and plural investigative techniques, primarily to make disadvantaged participants integral to the dialogical process. In this, it should be mentioned, Chambers is certainly more detailed, broad and inclusive than Habermas as to what constitutes modes and styles of expression in human communication. For Chambers, visual forms of communication, in particular, are 'not one-off exceptions but near-universals largely independent of culture or literacy' (1994b: 1256). However, having plural forms of communication begs the issue of arriving at equitable decisions. As Seyla Benhabib points out, consensus-based decisions require a regulative principle that governs "not only our deliberations in public but also the articulation of reasons by public institutions' (1996: 83, emphasis in the original). Even the exclusive use of visual communication in a PRA exercise will at some point run up against the need to deliberate and decide publicly between differing and better/worse visual representations.

As noted above, the absence of a regulating principle also deprives Chambers of any systematic way of checking power relationships in the PRA space. Chambers shares with Habermas the view that interlocutors can work their way past power relationships through public discussion. But to this end, Habermas comes equipped with both ideal speech situation and rational debate; Chambers does not. A similar conundrum arises when PRA is charged with adjudicating between conflicting claims. Here, Chambers explicitly acknowledges the problem. He declares that the 'identification, expression and resolution of conflicts of interest remain a frontier for participatory methods'. And he proceeds to offer this solution: 'Diagrams are promising as a means to defuse tension by making agreed fact visible and differences explicit, focusing public debate on physical things rather than on individual people. There remain both potential and need for better participatory methods for negotiation and equitable conflict resolution' (1994c: 1445). Accordingly, Chambers' answer to resolving competing claims in PRA is resorting, not to an adjudicating principle, but to more and better techniques. In keeping with his empiricist leanings underlined at the outset, Chambers seeks to resolve problems in PRA practice through more practice.

But such an answer once again skirts the question of ensuring the justness of PRA outcomes. In the absence of a grounding principle for deliberation, it is 
unclear how PRA moves anywhere beyond 'mere agreement'. If consensus there is, Chambers does not indicate how that consensus is the result of much more than an exchange of information and an accumulation of knowledge. PRA appears to provide no means of sifting through information or criticising what participants determine are erroneous or untenable claims. Moreover, without checks against unequal power relationships among participants, without critique, there appears to be little scope for preventing coerced outcomes. ${ }^{10}$ Thus Chambers is at pains to show how PRA's informality and inadequate regard for the quality of decision making guarantees against arbitrary decisions.

\section{Consensus and difference}

Both Habermas and Chambers acknowledge the importance of sociocultural pluralism (gender difference, cultural and sexual minority issues, multiculturalism, etc) and the importance of arriving at agreements despite difference. Habermas starts with value pluralism and proceeds to argue for a democratic proceduralism that yields an acceptable consensus. But he has been taken to task for erasing difference (Benhabib, 1996: 7-9; Fraser 1989, 1992; Young, 1996; Mouffe, 1999). The problem is that the very exercise of seeking a consensus risks using coercion and simplifying diversity. Representing community in unidimensional ways may facilitate the task of achieving results and solutions but, in so doing, it may also silence or exclude some community voices. Arriving at single and once-and-for-all decisions may thus tend towards obliterating the value pluralism that Habermas valorises in the first place.

Chambers, for his part, falls prey to these same criticisms. He asserts PRA's 'openness to complexity and diversity' (1994c: 1450) and believes its methodology to be consistent with the postmodern celebration of 'multiple realities and local diversity' (1994c: 1449; see also 1997: 188ff.). But he does not strike any balance between achieving consensus and respecting diversity. He speaks of community organisations 'reconcil[ing] differences' between people (1994b: 1259) and, to this end, recommends allowing 'people to address conflicts by putting down suggestions, and using markers to agree or disagree without needing to identify themselves. This "depersonalises conflicts and introduces informality where consensus is more easily reached"' (1994c: 1445). What remains unclear and unresolved is how much of 'reconciling differences' and 'depersonalising conflicts' amounts to an erasure/repression of difference and how much is the result of acceptable give-and-take.

As a way out of this impasse, Habermas's critics ${ }^{11}$ propose the following amendments and alternatives, which appear relevant to PRA. Jane Mansbridge modifies deliberative democracy by suggesting 'informal deliberative enclaves of resistance in which those who lose in each coercive move can rework their ideas and strategies, gathering their forces and deciding in a more protected space in what way or whether to continue the battle' (1996: 47). In the same vein, Nancy Fraser argues for 'subaltern counterpublics'. Like Mansbridge's 'informal deliberative enclaves', these are multiple deliberative spaces, but they are linked through alliances and networks (1992: 123). Chantal Mouffe goes further, rejecting deliberative democracy altogether. She writes that we need to 'give up 
the dream of a rational consensus' in the sense of a totalising and permanent consensus. Instead, she proposes a more open-ended 'agonistic pluralism', which is a "mixed game," ie, in part collaborative and in part conflictual and not as a [sic] wholly co-operative game as most liberal pluralists would have it' (Mouffe 1999: 750, 756). In all three of these proposals the implication is that consensus need not be, indeed should not be, single and once-and-for-all if difference is to be respected. Practically speaking, the idea is to have loosely linked, but plural and heterogeneous, tracks and solutions in social programming. Although it is outside the scope of this article to address them, many questions remain unsettled even here, not the least of which are questions about the institutional complexity and the additional resources that such multi-pronged programming implies.

To conclude this section, a brief consideration once again of the ends of the Chambers/Habermas comparative analysis just carried out. The purpose has not been to impose Habermas's views on Chambers' PRA. Even if one rejects communicative rationality because, among other things, of the inherent risk of erasing difference, the value of Habermas's work at the very least lies in raising questions about legitimating procedures and just outcomes in a participatory process. The weakness of PRA is the absence of any ground or mediating principle (let alone communicative rationality) for effecting legitimacy and justice. Thus, while Habermas and Chambers share a commitment to proceduralism, Chambers' is a comparatively thin proceduralism. Equipped with experience in the field, Chambers offers inclusiveness, informality and multiple PRA techniques. He recognises, and is concerned about, bad PRA practice. But his empiricism deprives him of theorising about principles that could ground such practice, yield qualitative decisions, and systematically check against arbitrariness and power inequalities.

\section{Questions of power}

Some of the power dimensions of PRA have been considered in the context of legitimacy, justice and difference, but it is necessary to examine them more broadly and in more detail. This section proposes to tease out Chambers' stand on power, its implications for political change, and its entanglements in the very framing of PRA.

\section{Change through voluntarism}

While Chambers ignores, for the most part, the issue of power in his influential 1994 articles, he rectifies this omission by devoting several pages to power in his later works $(1995 ; 1997: 76 \mathrm{ff}$.). Here, he speaks of power in the relationship between 'uppers' and 'lowers': 'Those who are powerful and dominant in a context are, then, "uppers" and those who are weak and subordinate are "lowers"' (1997: 58). For Chambers, individuals can be multiple 'uppers' or 'lowers', according to their age (young/old) or sex (male/female) and depending on where they are located geographically (urban/rural, north/south), professionally (eg teacher/student), institutionally (eg manager/staff) and so on (1995: 33ff.). 
But Chambers equivocates. On the one hand, as is implicit above, he appears to take a structural and relational view of power, seeing it located in multiple settings and being played out in the interactions between 'uppers' and 'lowers'. This view is reinforced by such statements as: 'changes [in power relations] between uppers and lowers can be positive-sum, with both gaining through a reduction in the power of uppers' (1997: 206). Reminiscent of Habermas (but minus his legitimating procedures), the statement suggests that power can be minimised through a dialogical and negotiated relationship.

On the other hand, Chambers appears to endorse a more agent-centred view of power, which locates power in individuals who intentionally control and use it (eg for strategic purposes, to impose their will on others, etc). The end here is the same as in the structural view of power-reducing power, particularly that of 'uppers' - but the prerogative of deploying power lies with the individual agent. Thus, speaking of the power of the bureaucrat, Chambers writes, 'What prevents him [the "upper"] learning in this case is not professionalism or bureaucracy. It is his dominant behaviour, person to person. It is his power' (1997: 75).

Yet, when it is time for PRA to effect political change, Chambers does not equivocate; he opts for the agent-centred view. He repeatedly underlines 'the primacy of the personal' in PRA (eg 1994a: 963; 1994c: 1450; 1997: 231ff.), so that rectifying power inequalities lies in personal transformation: 'Basic to a new professionalism [in PRA] is the primacy of the personal. This recognizes the power of personal choice, the prevalence of error, and the potential for doing better in this thing called development' (1997: 14). In addition, Chambers places the onus for such personal transformation entirely on 'uppers': 'Putting the first last is more radical. For it means that those who are uppers and powerful step down, disempower themselves, and empower others ... It implies that uppers have to give up something and make themselves vulnerable' (1997: 234).

Chambers' solution to the reversal of dominance is, therefore, a voluntaristic one, relying on the personal choice and behaviour of individual members of elite groups. He suggests a kind of behavioural training, in which 'uppers' listen, learn and refrain from lecturing, as an 'effective, interesting and fun' way of bringing about this change (1995: 39; 1997: 207-208). And he appears confident that, once this behaviour modification takes place, the personal satisfaction that 'uppers' derive from it will be spread, 'upwards, downwards, and laterally to their peers' (1995: 42).

What is puzzling about Chambers' position is that he takes great pains to emphasise PRA's group and participatory orientation, yet when it comes to issues of power he ends up focusing on individual change. Apart from being contradictory, the position is also questionable. First, Chambers does not specify why the 'upper' would agree to volunteer for behavioural training, and even if s/he did, why s/he would comply with this training or 'spread the word'. In other words, Chambers is at a loss to explain what compels such voluntarism. As previously, PRA trusts in an ungrounded, informal voluntarism that provides no systematic checks or guaranties against arbitrariness or non-compliance.

And second, Chambers fails to provide any role for 'lowers' in this process. Just as he did in 'reconciling differences' earlier, he appears to want to avoid conflict at all costs; and excluding 'lowers' in the reversal of domination seems 
to achieve this end. Yet, the participatory intent of PRA suggests that, where power inequalities exist, disadvantaged community members would need to identify these inequalities specifically (not leave 'uppers' to do so by themselves), attempt to address them (in dialogue with the 'uppers'), and ensure appropriate compliance (with, or perhaps even without, the co-operation of 'uppers'). This most probably would be a messy and tortuous deliberative process. Here, the power inequalities' identification phase would by itself be convoluted, requiring some collective analysis and agreement on the relevant political-economy and institutional locations of power. However, Chambers omits even this group learning phase, purportedly inherent to PRA, in his discussion of power.

\section{Power in PRA}

As indicated above, Chambers adopts a negative view of power, the idea being to eliminate or reduce it in the PRA space. To him, power is coercive and repressive. He writes that, 'For learning, power is a disability', and further that, 'All power deceives, and exceptional power deceives exceptionally' (1997:76). But the idea that power is a disability for learning and hence must be minimised suggests it can be uncoupled from learning so that learning can flourish unfettered. This conception misses the important Foucauldian argument that power can be positive and that power/knowledge implicate one another. ${ }^{12}$ For Foucault, power induces discourse/knowledge; by the same token, the framing of knowledge generates forms of power, ie control or surveillance mechanisms (1980: 98). This view is pertinent to, and has implications for, PRA.

Using the Foucauldian argument, Said (1978) and Escobar (1984/85) have shown how the framing of knowledge in colonialist and development circles happens through the implicit or explicit construction of binary opposites (eg Europe/Orient, self/other, North/South, developed/under-developed, etc). This construction, in turn, establishes power relationships, in which the first term is made primary and the second is beholden to it or ignored. In the remainder of the article, I would like briefly to probe three important dualisms deployed by PRA and the concomitant power relationships established. The point of the exercise is to suggest ways in which power is part and parcel of PRA, in spite of its attempts to banish power.

Localism. Localism is crucial to PRA, given the desire to move away from centralised development decision making. But, as Mohan and Stokke (2000) show, the resulting propensity is to romanticise and essentialise 'the local'. For example, 'there is a tendency to essentialism [sic] the poor and the social systems by which they operate. The "poor" are set against an unspecified "elite" whose only defining feature is their "non-poorness" ... Such binary ontologies undermine the stated intentions of PRA of seeking diversity' (2000: 253, 249; see also Mohan, 1999). Similarly, there is a proclivity to refrain from problematising 'local knowledge' as though it is naturally benign. Yet patriarchical community institutions, which prohibit women from inheritance and land rights, or parochialisms such as xenophobia, are far from incontestable. 
The other side of the championing of localism is the neglect or disparagement of the 'non-local'. Indicative of this neglect is, as already pointed out above, PRA's narrow view of power and its failure adequately to consider wider contexts in effecting change. Mohan and Stokke label this 'liberal populism', arguing that it results in downplaying local socioeconomic inequalities and ignoring broader national and global socioeconomic forces (2000: 249).

Privileging the public domain. PRA is by definition a public exercise; but as a consequence, it under-values the private sphere. This neglect is of particular relevance to feminists (Parpart, 2000; Mayoux, 1995) ${ }^{13}$ who believe that it can end up legitimising women's oppression in the home (ie the unequal domestic sexual division of labour). PRA attempts to stem the problem by using techniques such as 'household profiles', which aid in identifying domestic inequalities. Yet, as pointed out earlier, the lack of any critical and adjudicative principle in PRA sheds doubt on the usefulness of these techniques in dismantling patriarchical values and institutions. In effect, this deficiency places women's domestic problems outside the scope of PRA.

While under-valuing the private sphere, the public character of PRA privileges public communicative interactions. This, too, has feminist implications. Some cultures devalue women's public roles, impelling them to be passive relative to men. This passivity is reinforced if women are expected to raise in publicvisually or orally - sensitive issues such as sex, rape or violence (Mosse, 1994: 509-510; Mayoux 1995). Under these circumstances, women can either resort to letting men articulate their concerns, or, as David Mosse notes, they 'have to clothe their ideas and encode their desires in particular ways to make them heard and accepted as legitimate in the public domain of the PRA. But often, their particular concerns do not find a place in the consensus which a PRA generates' (Mosse, 1994: 515). Thus, concludes Jane Parpart, public interaction such as speaking 'can disempower if it removes the ability to control the dissemination of knowledge' (2000: 233).

Empowerment and panopticism. PRA depends on 'catalytic' institutions - be they NGOS, community/state organisations, or international development agencies-to facilitate local empowerment. Much pain is taken, as underlined earlier, to ensure that these organisations do facilitate, not extract, knowledge. What is not acknowledged, however, is how such facilitation is double edged: it may further empowerment (ie freedom), but it may also procure surveillance and discipline (ie constraint). This is what may be called, in the spirit of Foucault, PRA's 'panoptic' dimension. ${ }^{14}$ The public character of PRA begets disciplining mechanisms, where participants monitor and normalise one another's behaviour. In the example just cited, women 'encode' their communicative interactions in the presence of the larger community, particularly men. The presence of facilitating organisations may further reinforce this type of conduct. In the case of an outside-funded PRA programme especially, people will tend to say and do what they believe is expected of them (Mosse, 1994: 520; see also Cooke \& Kothari, 2001: chs 7,9). They may feel encouraged to work harder and deliver better results, or hide their disappointment when something promised is undelivered. 
PRA can thus become a type of spectacle, in which people perform roles under watchful eyes (their community's and those of the funding/facilitating agencies) thereupon re-defining identities and relationships.

PRA's power dimensions implicate the funding/facilitating institutions as well. Once PRA is adopted by organisations, it creates a new set of issues and problems for them to identify and manage (eg training, workshops, programme evaluation, etc). The generation of these new activities, in turn, will tend to give the organisations a strong interest in justifying, maintaining and propagating PRA (Rahnema, 1990; Mosse, 2001). If so, PRA's goal for outside organisations to hand over their responsibilities (ie work themselves out of the job) to local communities may be jeopardised. In fact, the use of PRA by state or international agencies could lead intentionally or unintentionally to the expansion, not diminution, of state or foreign power. A more nefarious outcome may even be the false use of PRA by state organisations to co-opt or monitor groups and communities seen as threatening (Nelson \& Wright, 1995: 10-11). The absence of critical or adjudicative mechanisms in PRA makes this outcome at least a possibility. But in any case, independent of whether PRA is well meaning or not, well done or not, the point is that it induces power and thereby transforms those (communities, institutions) who deploy it.

To conclude this section, I would like briefly to underscore Chambers' empiricist orientation vis $\grave{a}$ vis power. His focus on practice tends towards the adoption of a narrow view of power that, on the one hand, ignores or simplifies broad contexts and relations and, on the other, fails adequately to theorise about power or consider alternative conceptions of it (ie Foucauldian conceptions). These predilections are borne out by his agency-led, voluntaristic understanding of change, which, in contradiction to PRA's prime goal, cuts off learning and action on power inequality issues from social interaction (ie 'uppers' act on their own in relation to power inequality). His predilections are also demonstrated by the construction of binary opposites (local/non-local, public/private, freedom/ coercion). Here, the problem is not their construction per se (no conceptualisation can escape dualisms), but the power implications involved in privileging the first term and neglecting or repressing the second. There is nothing wrong with, and in fact much to applaud in, localism; the difficulty lies in essentialising localism, therein producing exclusions (of the 'outside'). Finally, Chambers' empiricist predilections are visible in his attempt to argue for 'pure' practice, in which knowledge and learning are uncoupled or neutralised from power. To his peril, he misses the fact that power is inherent in PRA itself, so that we cannot use it without it, in turn, using us. As discussed, PRA can enjoin both its agents (individuals and institutions who facilitate it) and its subjects (people and communities) to social or panoptic control.

\section{Conclusion}

Implicit in the above argument is the idea that, to the extent that Chambers is a scribe for organisations practicing PRA, the weaknesses identified in his work are weaknesses that may be reproduced in their practice. The absence of legitimating procedures and adjudicative/critical mechanisms, the problem of denying 
difference in the pursuit of consensus, and the inadequate conceptualisation of power will all tend to have a bearing on practice. It is possible that these gaps do not show up all the time in the field, perhaps because of the commitment and energy of some NGO and community leaders (therein depending more on personalities than procedures); however, there are no guarantees that the gaps do not, and will not, show up at least some of the time. (I have cited a few sources throughout the article confirming that they do, eg Mosse, 1994; Mayoux, 1995; White 1996; Parpart, 2000; Cooke \& Kothari, 2001). More work is needed in better theorising and systematising PRA, but also in further testing its limits in practice.

A final, related issue is that, in its present form, PRA can be easily misused or abused. Chambers repeatedly expresses concern over this eventuality throughout his work. At one level it cannot be prevented, as any ideology, methodology or programme takes on a life of its own and is thus corruptible. But, at another level, PRA leaves itself open to misuse and abuse because it provides too clean a depiction of practice, refraining, for the most part, from ruffling feathers and entering into the messy territory of politics.

\section{Notes}

Thanks to Kent Murnaghan, as always.

1 I am aware of only two recent sources (Parpart, 2000; and Mohan \& Stokke, 2000) that deal specifically with the theoretical underpinnings of Chambers' work on PRA. Parpart focuses primarily on the gender implications of PRA, and concludes that: 'PRA techniques, particularly as outlined by Robert Chambers, are undertheorized, especially in relation to power' ( $p$ 233). Mohan and Stokke analyse PRA as part of a trend in participatory development towards 'localism', which, they argue, downplays local socioeconomic inequalities and ignores broader national and global socioeconomic forces. I concur with both sources, but locate the weaknesses of PRA in its empiricist methodologica 1 orientation. It is this orientation that begets 'localism' and under-theorised gender/power relations, and also, as I argue, a lack of attention to crucial questions around legitimacy, justice and difference/consensus. I would like to point out that, by focusing primarily on the theorisation of PRA, and not its practice, my intention is not to reproduce in reverse Chambers' own practice/theory dichotomy. Rather, as just stated, the intention is to redress the balance in the PRA literature, which is heavily weighted in favour of identifying good or bad practice and against examination of its theoretical inclinations. Besides, the article will draw on some empirical literature where it helps to illustrate, develop or confirm a theoretical point.

2 The title of this article, a play on the expression 'the devil's in the details', is meant to convey precisely this idea, ie Chambers does not pay enough attention to the theoretical underpinnings, or details, of PRA.

3 These include the work of Paulo Freire and his followers, Rapid Rural Appraisal and applied anthropology (see Chambers, 1994a; 1994c).

4 Chambers' associates, Holland and Blackburn, define 'methodology' and 'method' in the following way: 'Methodology and approach are to be distinguished from method, which is a specific tool or technique. A method is not necessarily restricted to any one methodology' (1998: 5, emphasis in the original). Note that 'methodology' is used interchangeably with 'approach'. A methodology is broader than a method, in the sense that it is committed to a number of philosophical orientations; methods are a means to attain something. Thus PRA is a methodology/approach that contains a body of methods and techniques.

5 See, for example, Holub (1991) for an exposition of Habermas's public engagement with political issues, politicians, students and academics.

6 As noted in the previous section, Chambers is particularly concerned by the top-down development bureaucracy of the state and Western international development agencies.

7 Note that, of late, Habermas appears to prefer to employ the terms 'norms of discourse' or 'democratic procedures', but to avoid confusion I shall use 'ideal speech situation' throughout this article. 
8 Although, for Habermas, the ideal speech situation is based on structures inherent in human language and communication (Habermas, 1990: 43ff).

9 Habermas wishes to protect the public sphere from being colonised by outside corporate or state interests.

10 That is, no checks other than the deus ex machina of the PRA convenor, the dangers and contradiction $\mathrm{s}$ of which have been dealt with earlier.

11 These critics of Habermas need to be differentiated: as the remainder of this paragraph suggests, some, such as Benhabib, Mansbridge and Fraser are friendly revisionists who accept the broad outlines of his deliberative democracy but modify it. Others, such as Mouffe, are fully fledged critics who reject his deliberative democracy and propose an 'agonistic pluralism' instead. Although the former theorists accept deliberative democracy and hence some form of an adjudicative and communicative rationality, Mouffe's failure to do so leaves unresolved, for example, the question of how to adjudicate between pluralisms (ie what basis would we have to reject, say, xenophobia and neofascism, or to accept, say, ethnic nationalism?).

12 It is perplexing that Chambers misses this Foucauldian notion of power, as he contributes a chapter (1995) to a book that is devoted to power and participation, the introductory chapter of which specifically develops the notion (Nelson \& Wright, 1995: 9ff).

13 See also Seyla Benhabib (1996: 92-93) and Nancy Fraser $(1989,1992)$ for their criticisms of Habermas on the same issue.

14 Foucault sees Jeremy Bentham's vision of the panopticon-an architectural layout for a prison that allows a centralised supervisor to monitor all the inmates-to be indicative of modernity's surveillance and disciplining mechanisms. The goal, according to Foucault, is for the inmates to internalise this surveillance mechanism (1980: 148).

\section{References}

Benhabib, S (1996) Introduction: the democratic moment and the problem of difference; and Toward a deliberative model of democratic legitimacy, both in: Benhabib (ed), Democracy and Difference: Contesting the Boundaries of the Political, pp 3-18; 67-94 (Princeton, NJ: Princeton University Press).

Blackburn, J \& Holland, J (eds) (1998) Who Changes? Institutionalizing Participation in Development (London: Intermediate Technology Publications).

Calhoun, C (1992) Introduction: Habermas and the public sphere, in: Calhoun (ed), Habermas and the Public Sphere, pp 1-47 (Cambridge, MA: MIT Press).

Chambers, $\mathrm{R}$ (1994a) The origins and practice of Participatory Rural Appraisal, World Development, 22(7), pp 953-969.

Chambers, R (1994b) Participatory Rural Appraisal (PRA): analysis of experience, World Development, 22(9), pp 1253-1268.

Chambers, R (1994c) Participatory Rural Appraisal (PRA): challenges, potential and paradigm. World Development, 22(10), pp 1437-1454.

Chambers, R (1995) Paradigm shifts and the practice of participatory research and development, in: N Nelson \& S Wright (eds), Power and Participatory Development, pp 30-42 (London: Intermediate Technology Publications).

Chambers, R (1997) Whose Reality Counts? Putting the First Last (London: Intermediate Technology Publications).

Cooke, B \& Kothari, U (eds), (2001) Participation: The New Tyranny? (London: Zed Books).

Escobar, A (1984/85) Discourse and power in development: Michel Foucault and the relevance of his work to the Third World, Alternatives, 10, pp 377-400.

Foucault, Michel (1980) Power/Knowledge (ed Colin Gordon) (New York: Pantheon Books).

Fraser, N (1989) What's critical about critical theory? The case of Habermas and gender, in: Fraser, Unruly Practices: Power, Discourse and Gender in Contemporary Social Theory, pp 133-143 (Minneapolis, MN: University of Minnesota Press).

Fraser, N (1992) Rethinking the public sphere: a contribution to the critique of actually existing democracy, in: C Calhoun (ed), Habermas and the Public Sphere, pp 109-142 (Cambridge, MA: MIT Press).

Habermas, J (1989) Structural Transformation of the Public Sphere (trans T Burger) (Cambridge, MA.: MIT Press).

Habermas, J (1990) Moral Consciousness and Communicative Action (trans C Lenhardt \& S Weber Nicholsen) (Cambridge, MA: MIT Press).

Habermas, J (1996a) Three normative models of democracy, in: S Benhabib (ed), Democracy and Difference, pp 21-30 (Princeton, NJ: Princeton University Press). 
Habermas, J (1996b) Between Facts and Norms: Contributions to a Discourse Theory of Law and Democracy (trans W Rehg) (Cambridge, MA: Mrr Press).

Holland, J \& Blackburn, J (eds) (1998) Whose Voice? Participatory Research and Policy Change (London: Intermediate Technology Publications).

Holub, RC (1991) Jürgen Habermas: Critic in the Public Sphere (New York: Routledge).

Mansbridge, J (1996) Using power/fighting power: the polity, in: S Benhabib (ed), Democracy and Difference, pp 46-66 (Princeton, NJ: Princeton University Press).

Mayoux, L (1995) Beyond naivety: women, gender inequality and participatory development, Development and Change, 26, pp 235-258.

Mohan, G (1999) Not so distant not so strange: the personal and the political in participatory research, Ethics, Place and Environment, 2(1), pp 41-54.

Mohan, G \& Stokke, K (2000) Participatory development and empowerment: the dangers of localism, Third World Quarterly, 21(2), pp 247-268.

Mosse, D (1994) Authority, gender and knowledge: theoretical reflections on the practice of Participatory Rural Appraisal, Development and Change, 25, pp 497-526.

Mosse, D (2001) 'People's knowledge', participation and patronage: operations and representations in rural development, in: B Cooke \& U Kothari (eds), Participation: The New Tyranny?, pp 16-35 (London: Zed Books).

Mouffe, C (1999) Deliberative democracy or agonistic pluralism?, Social Research, 66(3), pp 745-758.

Nelson, N \& Wright, S (1995) Participation and power, in: Nelson \& Wright (eds), Power and Participatory Development, pp 1-8 (London: Intermediate Technology Publications).

Parpart, JL (2000) Rethinking participation, empowerment, and development from a gender perspective, in: J Freedman (ed), Transforming Development: Foreign Aid for a Changing World, pp 222-234 (Toronto: University of Toronto Press).

Rahnema, M (1990) Participatory Action Research: the 'last temptation of Saint Development', Alternatives, 15, pp 199-226.

Said, E (1978) Orientalism (New York: Vintage).

White, SC (1996) Depoliticising development: the uses and abuses of participation, Development in Practice, 6(1), pp 6-15.

Young, IM (1996) Communication and the other: beyond deliberative democracy, in: S Benhabib (ed), Democracy and Difference, pp 120-135 (Princeton, NJ: Princeton University Press). 